\title{
O DEVER DE MEMÓRIA DO ESTADO NO PROCESSO DE JUSTIÇA DE TRANSIÇÃO NO BRASIL*
}

\author{
Alessandra Lopes Camargo*
}

\begin{abstract}
Resumo: Este artigo reflete sobre a relação do Estado brasileiro com seu dever de memória no processo de justiça de transição. Analisa-se a luta pela anistia, a lei decorrente desse processo e seus efeitos sobre as memórias políticas na transição e na consolidação da democracia. Discorre-se sobre como esta lei manteve as memórias privatizadas e o Estado omisso de seu dever de memória. Reflete-se, também, sobre as recentes mudanças nas ações estatais que parecem recuperar o dever de memória do Estado no processo de justiça de transição no Brasil.
\end{abstract}

Palavras-chave: Memória política. Dever de memória. Justiça de transição. Direitos humanos. Anistia.

\section{The Duty to State memory in the Transitional Justice process in Brazil}

Abstract: This article reflects about the Brazilian government's relationship with its duty of memory in the transitional justice process. It analyzes the struggle for amnesty, the law resulting from this process and its effects on the political memoirs in the transition and consolidation of democracy. It discusses how this law remained privatized memories and the bankrupt state of its duty to remember. It is reflected also on the recent changes in state actions that appear to recover the state duty of memory in the transitional justice process in Brazil.

Keywords: Political memory; Memory duty; Transitional justice; Human rights; Amnesty.

\footnotetext{
* Agradeço pelas contribuições dos pareceristas anônimos que permitiram o aprofundamento e aperfeiçoamento da discussão apresentada no texto, bem como desse exercício árduo que é a escrita.

** Instituto de Filosofia e Ciências Humanas - Unicamp, Campinas-SP, Brasil (alefulana@gmail.com). Recebido em: 30/11/2014 - Aceito em: 03/09/2015.
} 
El Deber de memoria de Estado en el proceso de Justicia Transicional en Brasil

Resumen: En este artículo reflexiona sobre la relación del gobierno brasileño con su deber de memoria en el proceso de justicia transicional. Analiza la lucha por la amnistía, la ley resultante de este proceso y sus efectos en las memorias políticas en la transición y la consolidación de la democracia. Se discute cómo esta ley mantuvo recuerdos privatizados y el estado en silencio de su deber de memoria. Esto se refleja también en los recientes cambios en las acciones estatales que parecen recuperar el deber del Estado de la memoria en el proceso de justicia transicional en Brasil.

Palabras clave: Memoria política; Deber de la memoria; Justicia de transición;Derechos humanos; Amnistía.

\section{Introdução}

Em 2014 completou-se meio centenário da data de 31 de Abril de 1964, o golpe civil-militar que marcou o início de um longo período de arbítrio e autoritarismo no Brasil. Desde o fim desse regime até hoje, vivemos uma experiência democrática marcada, entre outros elementos políticos, por um inconcluso processo de justiça de transição (ELSTER, 2006; MEZAROBBA, 2003) do Estado com a sociedade no que se refere ao regime ditatorial. Até o início dos anos 2000, esse processo, que inclui as leis 9.140/95 e $10.559 / 02$, permaneceu nos marcos de uma reparação econômica e moral segundo Mezarobba (2003).

Contudo, percebe-se, nos últimos anos, uma mudança na ação do Estado, em especial na esfera do poder Executivo Federal, ao adotar uma perspectiva relacionada aos temas da justiça de transição no que se refere ao direito à memória e à verdade. Sob o governo de Luís Inácio Lula da Silva (PT) promulgou-se, ao final do ano de 2009, o III Plano Nacional de Direitos Humanos (PNDH) no qual consta o Eixo Orientador VI - Direito à Memória e à Verdade -, observando a necessidade de uma Comissão da Verdade. Esta orientação do PNDH foi legalizada, posteriormente, através da lei 12.528/11, que se tornou um importante instrumento de justiça de transição. Em um sentido oposto àquela "cadeia de negações" (SELIGMANN-SILVA, 2009), na qual a Lei de Anistia de 1979 tem sido a peça fundamental a atuar, surgem estas recentes iniciativas 
que, para Abrão e Torelly (2010) abre outro cenário frente às antigas reivindicações de memória, verdade e justiça (MEZAROBBA, 2007; 2010; BAUER, 2012; GRECO, 2009) encaminhadas ao Estado pelas vítimas da ditadura bem como seus familiares e grupos de direitos humanos.

Assim, tendo em conta que as políticas de memória são ações da justiça de transição (VASCONCELOS, 2009; BRITO; GONZÁLEZ; FERNANDEZ, 2004), interessa-nos, nesse artigo, levantar alguns elementos que nos ajudem a pensar como o Estado democrático brasileiro vem lidando com a questão do seu "dever de memória" em relação ao período da ditadura brasileira no processo de justiça de transição.

\section{Dever de Memória, justiça de transição e memória política}

Segundo Heymann (2007) a expressão "dever de memória" aparece no contexto específico da rememoração, nos anos de 1970 na Europa, do genocídio dos judeus durante a $2^{\text {a }}$ Guerra mundial. Mas foi apenas nos anos 1990 que este conceito se tornou corrente no meio acadêmico e político, a princípio na França. Ele traz a ideia de que as memórias de dor e sofrimento geram obrigações por parte do Estado, e mesmo da sociedade, para com as vítimas ou grupos de vítimas. Ricoeur (2003) fala que o dever de memória, enquanto reapropriação de um passado, é uma noção moral. Heymann (2007) ainda menciona que, enquanto categoria política, a expressão "dever de memória" opera como um instrumento de reivindicação por parte de diversas minorias oprimidas e excluídas.

Através da memória, exige-se o reconhecimento da dor e a formulação de direitos específicos às vítimas. Assim, o "dever de memória", enquanto paradigma conceitual, nos remete ao mesmo tempo a um imperativo moral e político: moral no sentido de que torna inadmissível a aceitação de crimes que geram opressão, violência e sofrimento; político porque abre espaço para pensar em políticas públicas específicas cujo objetivo deve ser de tratar um passado marcado por diversos sofrimentos e que continuam 
reverberando sob a forma de legados no presente. Portanto, o "dever de memória" contém uma dupla implicação. Primeiro: o direito das vítimas de rememorar seu passado, narrar suas memórias e compartilhá-las socialmente, ou seja, o direito ao reconhecimento social da existência dessa história de traumas. Segundo, que se desenvolve em decorrência da primeira implicação: essas memórias de sofrimento geram deveres por parte do Estado e da sociedade para com as vítimas.

Heymann (2007) mostra que a prática do "dever de memória", na França, trouxe à luz uma "matéria-prima de indignação social". Conhecer a fundo os horrores do holocausto, por exemplo, gerou um imperativo moral que torna socialmente inadmissível esse instrumento de dominação. Assim, essas memórias de sofrimento articuladas pelo trabalho de memória (JELIN, 2002) criaram um valor compartilhado socialmente. Greco (2009) corrobora com este argumento ao afirmar que a transformação da vivência em experiência e desta em conhecimento compartilhado pela sociedade só pode ser desenvolvida pela memória trabalhada no espaço público.

Dessa forma, na prática política percebemos que esse "dever de memória" só pode se concretizar caso as vítimas sejam capazes de traduzir suas experiências em memória na esfera pública. Por isso, o paradigma do "dever de memória" é contraditório e conflituoso uma vez que nem sempre é possível à vítima narrar uma experiência traumática. Se consideramos que a narrativa é, de alguma maneira, uma forma de trazer para o presente a experiência passada (HALBWACHS, 2004), isso pode justificar o silenciamento das próprias vítimas (POLLACK, 1989), pois o testemunhar pode constituir uma violência para elas, como aponta Quartim (2013) em seus estudos sobre autobiografia da resistência à ditadura. Assim, o "dever de memória" do Estado e da sociedade enfrenta-se com o direito ao esquecimento das vítimas (Ricouer, 2003). Portanto, o direito ao olvido (direito ao esquecimento) nos processos individuais e políticos (TODOROV, 2000) ${ }^{1}$ defronta-se

${ }^{1} \mathrm{O}$ tema sobre o esquecimento acompanha os estudos sobre memória e é parte 
com o "dever de memória" do Estado e da sociedade. Contudo, Heymann (2007) lembra que os julgamentos, na França, contra os colaboradores franceses ao extermínio de judeus, ressignificaram o papel do testemunho e incentivaram outras vítimas a compartilhar as memórias de suas experiências.

Podemos pensar também que existem outros elementos que criam condições favoráveis para a emersão das memórias subterrâneas ${ }^{2}$ na esfera pública (POLLACK, 1989). Acreditamos que contextos protegidos legalmente por políticas de memória, bem como a pressão de grupos de direitos humanos sobre os governos são alguns elementos que podem trazer segurança necessária para que as vítimas consigam reelaborar seu trauma pessoal através de uma perspectiva coletiva e social.

Portanto, podemos inferir que há uma relação complexa entre o "dever de memória" e a gestão de passados traumáticos nos processos de democratização. Ricouer (2003) lembra que o dever de memória apela para uma política de memória e Pollak (1989) chama a atenção para o problema organizativo do trabalho de memória. Essas observações nos colocam frente à problemática de como o Estado, enquanto ator político heterogêneo (TATAGIBA; ABERS; SERAFIM, 2014), trata o legado do passado bem como suas responsabilidades em relação aos crimes cometidos por agentes estatais. Por isso, o modo como o Estado entende o papel das memórias políticas, a importância que atribui a elas, o espaço político e a forma institucional que desenvolve para que elas possam vir à arena pública, influencia o desenho e o conteúdo das iniciativas e leis que tratam as questões do passado traumático, bem como seu impacto sobre a implantação e consolidação dos valores democráticos, ou de um "senso comum democrático" como observou Torelly (2010). Este problema tem sido estudado pelo campo da justiça de transição (TEITEL, 1996; BRITO;

fundamental das discussões sobre os legados das ditaduras nas democracias da América Latina. Sobre isso ver também Telles (2009).

${ }^{2}$ Conceito que Pollack (1989) utiliza para discutir memórias que permaneceram silenciadas após governos autoritários. 
GONZÁLEZ; FERNÁNDEZ, 2004; ELSTER, 2006; MEZAROBBA, 2009; SANTOS, 2009).

Há um consenso nesta literatura que coloca sobre o Estado uma responsabilidade fundamental no combate às violações do passado. Segundo esta teoria, este é o ator principal que pode impulsionar ou retardar o avanço de medidas legais de memória, verdade e justiça. $\mathrm{O}$ tipo de transição, as crenças e valores das lideranças políticas, a força dos grupos reformistas, o papel das igrejas, a persistência de enclaves institucionais autoritários - como leis de anistia - são variáveis que ajudam a entender como os Estados lidam com seus passados de violações (BRITO; ENRÍQUEZ; FERNÁNDEZ, 2004).

Apesar de ser uma teoria e um campo de estudo específico ainda em desenvolvimento, a Justiça de Transição demonstra um esforço intelectual para mobilizar um debate de intersecção entre o campo da democratização, direitos humanos e reconstrução estatal pós-ditaduras (QUINALHA, 2013). No entanto, por utilizar amplamente o quadro conceitual da transitologia, herda algumas de suas limitações teóricas, como o uso de uma concepção de democracia eleitoral e o não reconhecimento da heterogeneidade da sociedade civil e do Estado. Aqui a memória aparece como um direito humano tanto das vítimas dos regimes violentos como da sociedade no geral.

Desse modo, apesar de colocar o problema da memória no campo dos direitos humanos, não desenvolve suficientemente o papel das políticas de memória no processo de construção democrática, mas deixa claro que o Estado é um ator fundamental na garantia desse direito. De qualquer maneira, podemos, mesmo que de forma ensaística, afirmar que existe uma interação teórica e política entre a teoria da Justiça de Transição e o conceito de "dever de memória".

Assim sendo, do desdobramento dessa interpretação sobre o "dever de memória" e sua relação com a noção de justiça de transição, podemos compreender a memória política (POLLAK, 1989) enquanto um instrumento político de dupla determinação "direito-dever" que atua nos processos de justiça de transição e que 
coloca diversos atores em interação. Ela aparece como ferramenta de desobstrução de um ciclo de silenciamentos institucionais e invisibilidade pública (SELIGMANN-SILVA, 2009) a que as vítimas e suas memórias foram submetidos.

Nos contextos de países que viveram experiências ditatoriais, como os da América Latina, o uso desta memória, em especial pelos movimentos sociais, parece ter se conformado como um instrumento fundamental de busca por justiça frente aos crimes de lesa-humanidade perpetrados pelo Estado ditatorial (BRITO, 2004). Dessa forma, todo o processo que considera a questão de como o Estado trata os crimes de lesa-humanidade cometidos por agentes estatais durante dos regimes militares é atravessado pelo problema da memória política.

\section{A memória política contra o esquecimento: a luta e a lei de Anistia}

Na transição brasileira, Del Porto (2002) salienta que as disputas pela abertura política se iniciaram nos anos 1970 com a luta pela Anistia, que defendia a necessidade do Estado de Direito e a defesa dos direitos humanos. Greco (2009) afirma que o Movimento pela Anistia resgatava a partir da memória política o terror de Estado e a luta contra a ditadura. Assim, o movimento assumiu como estratégia a construção de uma contramemória ou um contradiscurso em oposição à versão de memória instituída pelos militares imposta através da diluição das memórias coletivas e da negação das memórias individuais. Essa operação política de silenciamento é a estratégia de esquecimento que o regime militar adotou como método de governo (GRECO, 2009) nos 21 anos de vigência no Brasil. Assim, na batalha entre Governo Militar e Movimento de Anistia, pelo conteúdo da Lei de Anistia, a memória política impulsionada pelo movimento foi condição fundamental para enfrentar as "verdades oficiais" instituídas pelos militares e para abrir espaço às demandas democráticas no Estado ditatorial.

Assim, podemos inferir que, diante da sua obrigação de "dever de memória", o Estado brasileiro, na transição, respondeu 
autoritariamente com o silêncio institucional (BAUER, 2012) e com a negação da possibilidade de socialização e compartilhamento das experiências traumáticas. Com isso, provocou um bloqueio do trabalho de memória sobre o regime militar e seus crimes de lesa-humanidade na arena pública. Portanto, a técnica operacional de dominação foi o silêncio. Para controlar a memória política e produzir uma versão com caráter de verdade oficial requerse o silêncio do Estado, das vítimas e da sociedade. Do silêncio construído através de procedimentos violentos, emerge o discurso instituído, ou ainda, a "memória oficial" do regime. Como disse Arendt (2013), uma orquestração da mentira organizada, da falsificação da história ou da negação totalitária da verdade fatual.

Dessa forma, podemos afirmar que a estratégia do esquecimento é uma operação política que procura hegemonizar e homogeneizar a memória de forma a relegar outras memórias rivais (JELIN, 2002) ao ostracismo, ao isolamento e à privação de espaços públicos de elaboração e interpretação. Portanto, inferimos que o efeito mais geral deste processo é a privatização das memórias (BAUER, 2012) que se desenvolve através da ausência de possibilidades de compartilhamento social das experiências, projetos políticos e traumas individuais e coletivos. Alguns intelectuais (MEZAROBBA, 2003; BAUER, 2009; TELES, 2009) têm afirmado que a postura de determinados setores da sociedade brasileira em não tomar parte dos embates, das pautas e demandas das vítimas pode estar relacionada com esse processo ${ }^{3}$.

Apesar desta estratégia de dominação, é verdade que os militantes que pertenceram à resistência ao regime, bem como grupos de familiares de mortos e desaparecidos e organizações de direitos humanos, têm lutado arduamente contra a amnésia. Se o silêncio institucional perdurou, e ainda perdura em algumas esferas do poder, no âmbito da cultura podemos listar uma infinidade de iniciativas que procuraram "desprivatizar" a memória política sobre o período (ROLEMBERG, 2006). No plano

\footnotetext{
${ }^{5}$ Tema que merece análise mais aprofundada, mas que não será feita aqui à medida que foge ao escopo desta investigação.
} 
da busca por justiça, através de instrumentos legais, também poderíamos contabilizar diversas iniciativas, como por exemplo, o caso da Guerrilha do Araguaia (SANTOS, 2009).

Nesse sentido, foi contra esse mecanismo de "privatização das memórias" que o Movimento pela Anistia se insurgiu no contexto da transição brasileira. Foi uma tentativa política de imprimir outro significado à anistia. Ou seja, não se tratava de "perdoar" os "crimes políticos praticados pelos subversivos", como os militares propalaram com a lei de 1979. Sobretudo, tratava-se de reconhecer, através de um debate público, as ações de resistência ao regime militar como não-crimes e garantir, pela difusão de um valor democrático de tolerância e respeito a diversidade de ideologias e projetos, um futuro no qual o dissenso não fosse criminalizado.

Por isso, a luta pela anistia foi uma batalha pelo direito à memória política e pela democracia. Mais que isso, foi uma luta pelo reconhecimento ao direito de resistência contra um regime violador de direitos políticos, civis e sociais. De alguma maneira, mesmo que o léxico do movimento jamais tenha sido o de "dever de memória", a prática política já apontava, em meados dos anos 1970, o "dever de memória" que deveria ser cumprido pelo Estado violador. Contudo, como é consenso na literatura, a Lei de Anistia não refletiu o projeto político do Movimento de Anistia.

Ao invés de atender às demandas da sociedade civil organizada, o Estado agiu de um modo que reafirmou o discurso da segurança nacional ao deixar de fora da anistia os atos considerados crimes de sangue, ao não ter reconhecido as mortes com a declaração de ausência para os "desaparecidos", ao ter criado a figura jurídica dos crimes conexos e, por fim, ao ter discursado com o argumento da reciprocidade ou "perdão recíproco". Difundida e mitificada como uma lei de reconciliação nacional, a ponto de anular a multiplicidade das memórias políticas dos diversos atores políticos, a lei de Anistia funcionou como continuidade da mesma engrenagem de negações do regime militar, consubstanciando o silêncio em relação aos horrores da ditadura no processo de transição à democracia (GRECO, 2009). 
Como legado à democracia, deixou uma conta aberta, uma memória sem voz, uma herança sem testamento, como diria Arendt (2013). O Estado não reconheceu a existência dos crimes estatais, igualou seus crimes de lesa-humanidade aos atos políticos de resistência ao regime e, com essa garantia de impunidade aos perpetradores, seguiu para as demais políticas transicionais feitas em acordo com algumas lideranças políticas democráticas.

\section{Os governos democráticos nos anos 1990 e o dever de memória política}

Segundo os estudiosos da teoria da transição, os pactos de transição que possibilitaram a passagem ao regime democrático envolveram garantias de interesses fundamentais que beneficiaram os agentes do regime autoritário. Um desses interesses é justamente garantir que o "passado não será desenterrado" (O'DONNEL; SCHMITTER, 1988: 55) Assim, as demandas por memória, verdade justiça, no contexto da transição democrática, foram considerados uma barreira para a democratização. Essa interpretação, entre as elites pactuantes, sobre o papel do passado no presente pode ter funcionado como um constrangimento político para o avanço de medidas de justiça de transição no Brasil (MEZAROBBA, 2010; QUINALHA, 2013).

Assim, a relação do Estado democrático com a memória política sobre os crimes do Estado ditatorial, no momento inicial da transição, é marcada pela continuidade de uma postura conservadora e negacionista, uma vez que não houve iniciativas institucionais imediatas de políticas de memória para que o "dever de memória" do Estado pudesse ser cumprido. Não se viabilizou institucionalmente o discurso, a fala e o compartilhamento das experiências de trauma.

No entanto, apesar de um contexto de tentativa de silenciamentos por parte do Estado, não podemos afirmar que houve um esquecimento efetivo do passado. Ao contrário. Não é possível esquecer o que se viveu. Projetos como Brasil Nunca Mais, 
publicado pela primeira vez quatro meses após a retomada da democracia, cumpriu um papel político que poderíamos afirmar como corajoso e fundamental para a possibilidade do trabalho da memória política no Brasil ${ }^{4}$.

Apesar desse contexto inicial, dezesseis anos após a Lei de Anistia, abre-se uma novidade institucional e legal que altera as relações entre Estado e sociedade no que se refere aos crimes contra os direitos humanos cometidos pelo regime militar. A primeira lei que trata dessas violações é a 9.140/95, que responde à questão de mortos de desaparecidos políticos criando no âmbito do Estado uma comissão especial para julgar casos de reparação. Nessa lei, o Estado assume sua responsabilidade com as famílias pelo desaparecimento e morte de seus entes, mas estas, por sua vez, devem assumir o ônus das provas.

É a primeira vez que o Estado assume sua responsabilidade frente aos crimes de lesa-humanidade e concede alteração no sentido de ampliação da Lei de Anistia de 1979 (MEZAROBBA, 2003). No entanto, os perpetradores continuaram sob o manto da impunidade na medida em que o governo de Fernando Henrique Cardoso (1994-2002) permaneceu com a defesa das limitações da lei 6.683/1979. Em seguida, em 2002, por pressão de grupos de familiares e de direitos humanos, o mesmo presidente sancionou a lei 10.559 que possibilitou a reparação econômica também para aqueles que foram impedidos de exercer suas atividades profissionais por força da perseguição e do arbítrio. Para realizar a averiguação e julgamento dos processos criou-se, no âmbito do Ministério da Justiça, a Comissão de Anistia. Aqui também o ônus da prova caberia às vítimas.

Neste ponto, é possível inferir que, embora o Estado democrático tenha conseguido sair do papel de violador para o de promotor dos direitos humanos, no que se refere às questões relacionadas à gestão do passado autoritário e dos crimes de lesa-

\footnotetext{
4 Para mais informações ver "Brasil Nunca Mais Digital". Disponível em: <http://bnmdigital.mpf.mp.br>. Acesso em: 29 nov 2014.
} 
humanidade, esse papel permaneceu limitado ${ }^{5}$. O Estado não impulsionou uma política de memória que possibilitasse o debate público e coletivo das memórias particulares das vítimas, uma vez que o espaço para a elaboração da memória ficou limitado por provas burocráticas e individuais. O Estado atuou como um depositário das memórias individuais, mas não um ator ativo na construção e no estímulo de "outra memória possível", agiu como reparador econômico, mas perdeu a chance de ser um agente educativo. Frente à sociedade, entendida na sua generalidade, as memórias permaneceram privatizadas, como sugere Bauer (2012).

Podemos pensar que esta postura política por parte do Estado teve consequências fundamentais para a democracia, a saber: ao deixar o ônus da prova a cargo dos familiares e vítimas, o Estado impulsionou um despertar do dever de memória no seu aspecto testemunhal, mas não alavancou um processo que garantisse o direito à memória política das vítimas e seus familiares na esfera pública, de modo que não houve um compartilhamento social das experiências com o passado de sofrimento causado pelas violações cometidas pelos agentes do Estado. Assim, perdeu-se a oportunidade de produzir um efeito pedagógico de aprendizagem de valores democráticos. Enquanto ator político, o Estado calouse frente "ao espírito" da lei de anistia e deixou de realizar efetivamente seu dever de memória.

\footnotetext{
${ }^{7}$ Embora o Estado democrático de direito tenha avançado na elaboração de políticas de justiça de transição, ele continua sendo um grande violador de direitos humanos em especial quando se discute o papel das forças repressivas. Casos atuais como a tortura, desaparecimento e morte de Amarildo Dias de Souza, no Rio de Janeiro em 14 de julho de 2013 durante ação da polícia na comunidade da Rocinha, mostram que a discussão sobre o papel do Estado democrático na garantia dos direitos humanos é muito complexa e merece pesquisas aprofundadas e muita disposição de luta por parte da sociedade. Sobre isso, ver entrevista com Cecília Coimbra na Revista Verdade, Memória e Justiça. Disponível em: http://goo.gl/ImyorN. Acesso em 08 abr. 2015.
} 


\section{Os anos 2000 e um novo cenário para outras políticas ${ }^{6}$}

A partir da segunda metade dos anos 2000, inicia-se um cenário no qual a Lei de Anistia passa a ser questionada no âmbito estatal, por atores da sociedade civil e do próprio Estado, abrindo uma perspectiva de "desprivatização" da memória política e de novas iniciativas estatais voltadas ao direito à memória.

Em 2008, a Ordem dos Advogados do Brasil (OAB) impetrou uma Ação de Descumprimento de Preceito Fundamental (ADPF), no Supremo Tribunal Federal (STF) na qual questionou a validade da interpretação da Lei de Anistia para casos de crime de lesa-humanidade, imprescritíveis e não anistiáveis segundo legislação internacional ${ }^{7}$ (DIENSTMANN, 2010). Ainda em 2010, foi divulgada sentença da Corte Interamericana de Direitos Humanos em relação ao caso Gomes-Lund, mais conhecido como caso da Guerrilha do Araguaia, que condena o Estado brasileiro a investigar os fatos, julgar e, caso fossem apontados os culpados, punir os responsáveis ${ }^{8}$.

Situações como estas colocaram em pauta na agenda do Estado brasileiro a questão sobre a memória do passado autoritário e suas atuais políticas de direitos humanos relativos aos crimes de lesa-humanidade. Nesse novo cenário, o Estado, através do poder executivo e de alguns de seus órgãos, responderam, de maneira inovadora, com algumas iniciativas relacionadas à memória política: 1 - Projeto direito à memória à verdade da Secretaria Especial de Direitos Humanos (SEDH) - Publicação do livro-relatório "Direito à Memória e a Verdade - Comissão Especial de Mortos e Desaparecidos", publicação oficial com a chancela do Estado brasileiro em 2007 que atribui aos agentes da

\footnotetext{
${ }^{6}$ Essa seção do artigo é parte de uma incipiente observação acerca das transformações que impulsionaram as iniciativas e políticas da memória.

${ }^{7}$ Matéria julgada em 2010, o STF manteve a validade da Lei 6.683/1979.

${ }^{8}$ Disponível em: http://www.corteidh.or.cr/docs/casos/articulos/seriec_219_ por.pdf. Acesso em: 08 abr. 2015.
} 
ditadura crimes de tortura, estupro e todo tipo de violação aos direitos humanos; 2 - Projeto Marcas da Memória da Comissão da Anistia desenvolvido a partir de 2008; 3 - Audiência pública sobre "Limites e Possibilidades para a Responsabilização Jurídica dos Agentes Violadores de Direitos Humanos durante o Estado de Exceção no Brasil", que discutiu a interpretação da Lei de Anistia de 1979, promovida em julho de 2008 pelo Ministério da Justiça e a Comissão de Anistia; 4 - Projeto Memórias Reveladas desenvolvido por iniciativa da Casa Civil em 2009.

Ainda em 2009 ocorre o lançamento do III Plano Nacional de Direitos Humanos. Um programa que apresentou de maneira inédita o "direito a memória e verdade" como um dos seus eixos norteadores propondo a criação da Comissão Nacional da Verdade ${ }^{9}$. Isso demonstra uma postura do Poder Executivo, e de alguns órgãos de Estado, que avança no cumprimento do seu "dever de memória" e no aprofundamento do processo de justiça de transição (ABRÃO; TORELY, 2011).

Além disso, é importante lembrar que é cada vez maior a influência das instituições internacionais nos processos de justiça de transição de cada país, como afirma a autora Roth-Arriaza (2004) atestam algumas sentenças de Cortes Internacionais. No início de 2001, a Corte Interamericana de Direitos Humanos, por exemplo, proferiu uma sentença contra o Peru na qual sustentou que as leis de autoanistia não são legítimas porque foram feitas pelos próprios violadores. A sentença é reafirmada em 2006 nos casos contra o Chile e novamente contra o Peru. Estas influenciaram os processos jurídicos no Brasil. Em 20 de Junho de 2003, na 1a. Vara da Justiça Federal do Distrito Federal foi proferida decisão em favor dos autores para o caso sobre a Guerrilha do Araguaia que tramitava desde 1982 tendo sido esta decisão fundamentada em normas constitucionais e na jurisprudência da Corte Interamericana de Direitos Humanos (SANTOS, 2009: 489).

\footnotetext{
${ }^{9}$ A Comissão Nacional da Verdade foi regulamentada através da Lei 12.528/2011 e instituída em 16 de maio de 2012.
} 
Para além dos motivos expostos acima, acreditamos que cabe uma reflexão ensaística sobre os fatores que levaram órgãos do Estado a essas iniciativas. Acreditamos que existem outros motivos, para além das pressões das Cortes Internacionais que, agindo em conjunto, geram oportunidades políticas favoráveis a estes avanços. Primeiro, com a vitória do Partido dos Trabalhadores para o Governo Federal, chegaram ao poder, assumindo postos de liderança no âmbito do poder executivo, diversos líderes ligados aos movimentos sociais e de direitos humanos.

Assim, segundo Tatagiba, Abers e Serafim (2014), em seus estudos sobre políticas públicas de moradia, essa conjuntura criou uma estrutura de oportunidades para que os militantes históricos, através de cargos burocráticos, pudessem atuar nos principais ministérios e secretarias como o faziam antes, nos movimentos sociais. Ou seja, para essas autoras, os militantes "transformaram as agências governamentais em espaços de militância nos quais continuaram a defender bandeiras desenvolvidas no âmbito da sociedade civil" (TATAGIBA; ABERS; SERAFIM, 2014: 326). Ainda segundo as estudiosas, essa relação produziu interações diferentes entre sociedade civil e Estado e aumentou a capacidade de influência dos movimentos sociais nas ações do Estado, com variações setoriais evidentemente.

Ainda sobre os atores, D'Araújo (2009) fez um estudo etnográfico das elites dirigentes nos dois governos Lula e apontou que na trajetória política dessas personalidades há uma origem ligada aos movimentos sociais. Por exemplo, $45 \%$ dos ministros do governo Lula participaram de alguma maneira desses movimentos. Evidentemente, para a área de Justiça de Transição, precisaríamos fazer um estudo de maior fôlego, o que não caberia nesse artigo, mas podemos apontar algumas observações empíricas dentro dessa chave explicativa.

Nesta linha, convém um destaque ao Ministro da Secretaria Especial de Direitos Humanos (SEDH), Paulo Vannuchi, durante os dois mandatos do governo Lula (2003-2010), em que esteve à frente da elaboração do PNDH III. Vannuchi é um militante histórico em defesa dos direitos humanos e atuou no Projeto Brasil Nunca Mais, 
já citado nesse artigo. Outra menção, Tarso Genro, ex-ministro da Justiça, foi perseguido politicamente e atuou na luta por direitos humanos na redemocratização. Não menos importante, a própria Dilma Rousseff, ex-perseguida política, à época ex-ministra da Casa Civil no momento da implementação do Projeto Memórias Reveladas ${ }^{10}$.

Por fim, acreditamos também que outra variável explicativa pode encontrar-se nas mudanças de paradigma acerca do papel que cumpre a memória política nos processos de democratização. Para Elster (2009) as políticas dependem das crenças e valores que estão em jogo nos processos políticos. Como dissemos nas seções anteriores, no momento da transição o medo do regresso autoritário fez com que a memória política fosse interpretada como um elemento de desestabilização dos pactos e acordos que marcaram a passagem da ditadura para a democracia. No entanto, tanto o paradigma de justiça de transição e seu receituário quanto o conceito de "dever de memória" trazem uma perspectiva positiva sobre a memória política e sua relação com os valores e processos do regime democrático. Ou seja, uma dimensão paradigmática oposta àquela do momento imediato da transição.

Parece-nos que o Ministério da Justiça e a Comissão da Anistia têm assumido a perspectiva teórica da justiça de transição nos últimos anos, o que pode estar contribuindo para o desenvolvimento de iniciativas de socialização das memórias políticas e para o cumprimento do "dever de memória" que o Estado tem com as famílias, com as vítimas e com a sociedade. Criada para operar a Lei 10.559/2002, a Comissão de Anistia superou suas responsabilidades iniciais promovendo projetos educativos e teóricos na área de justiça de transição, como Seminários sobre Justiça de Transição, sobre Comissão da Verdade, bem como a organização e publicação da revista Anistia Política e Justiça de Transição que já está no seu oitavo número e é publicada desde Agosto de 2009. Além dessas iniciativas, organiza ainda os Projetos

\footnotetext{
${ }^{10}$ Para saber mais: Centro de referência das lutas políticas no Brasil (19641985). Disponível em: <http://goo.gl/PM8ksD>. Acesso em 22 ago 2015.
} 
Marcas da Memória, com objetivo de difusão cultural da memória e as Caravanas da Anistia com a enunciação pública de propósito educativo e de socialização das memórias políticas através dos testemunhos públicos durante os processos de julgamento dos pedidos de anistia (COELHO; ROTA, 2012; ROSITO, 2010).

\section{Conclusão}

Ao longo deste texto procuramos refletir sobre a relação do Estado democrático brasileiro com a memória política do período ditatorial. A mobilização do conceito de "dever de memória" procurou mostrar que diante dos testemunhos de sofrimento e violência se impõe a obrigação do Estado frente às vítimas e mesmo com a sociedade, a fim de garantir dignidade, respeito e um senso ético de inadmissibilidade em relação às violações contra dos direitos humanos. No Brasil, a Lei de Anistia de 1979 funcionou como um bloqueio ao trabalho de memória criando um constrangimento institucional à ação das lideranças políticas e do estabelecimento de profundas medidas de justiça de transição.

O'Donnell e Schimitter (1988) sustentam que, frente ao medo do regresso autoritário, o silêncio sobre o passado foi a estratégia que garantiu o pacto transicional. Assim, a lei atuou como a continuidade do paradigma da lógica da segurança nacional na nascente democracia através da operação do silêncio institucional e da "privatização" das memórias. Este mecanismo operatório foi mantido no conteúdo das leis de reparação pecuniária, em especial a 9.140/1995, durante os governos de FHC - embora o contexto fosse de recuperação dos direitos humanos com os dois primeiros PNDHs.

No entanto, podemos afirmar que nos últimos anos iniciouse uma transformação nas ações do Estado brasileiro. De Estado ouvinte e depositário de memórias privadas presenciamos, particularmente através da atuação da Comissão de Anistia, uma inovação em direção aos temas e concepções desenvolvidas pela justiça de transição que o transforma em ator promotor e produtor 
de memórias. Alguns órgãos do Estado brasileiro passam a atuar com outro entendimento acerca do papel da memória política a de um instrumento fundamental para o aprofundamento dos direitos humanos e para o fortalecimento do Estado democrático de direito.

As variáveis explicativas dessa mudança, que aparecem de forma ensaística nesse artigo, estão na chave das pressões exercidas pelas Cortes Internacionais, pela ascensão das lideranças ligadas aos movimentos sociais de direitos humanos, por sua trajetória de ex-perseguidos políticos e pelas mudanças de paradigma acerca do papel da memória política para a democracia. Como afirmam Brito, González e Fernández (2004), a construção da democracia é atravessada pelas políticas de memória. Cremos, dessa forma, que o Brasil caminha para o aprofundamento de valores de um regime tão arduamente conquistado.

\section{Referências}

ABRÃO, P., TORELLY, M. Justiça de Transição no Brasil: a dimensão da reparação. Revista Anistia Política e Justiça de Transição. Brasília: Ministério da Justiça, n. 3 jan. / jun, 2010, pp. 108-139.

ABRÃO, P.; TORELLY, M. As dimensões da Justiça de Transição no Brasil, a eficácia da Lei de anistia e as alternativas para a verdade e a justiça. In. ABRÃO, P.; TORELLY, M.; PAYNE, L. A. (Orgs.). A Anisitia na Era da responsabilização: o Brasil em perspectiva internacional e comparada. Brasília, Ministério da Justiça, Comissão de Anistia; Oxford: Oxford University, Latin American Centre, 2011.

ARENDT, H. [1954]. Entre o passado e o futuro. 7a. Edição. São Paulo: Perspectiva, 2013.

BAUER, C. S. Brasil e Argentina: Ditaduras, desaparecimentos e Políticas de memória. Porto Alegre: Editora Medianiz, 2012. 
BRITO, A. B.; GONZÁlEZ, C.; FERNÁNDEZ, P. A. (Orgs.) A política de memória: verdade e justiça na transição para a democracia. Lisboa: Instituto de Ciências Sociais, 2004.

COELHO, M. J. H.; ROTTA, V. (Orgs). Caravanas da anistia: o Brasil pede perdão. Brasília: Ministério da Justiça; Florianópolis: Comunicação, Estudos e Consultoria, 2012.

D'ARAUJO, M. C. A elite dirigente do governo Lula. Rio de Janeiro: CPDOC, 2009.

DEL PORTO, F. B. A luta pela Anistia no Regime Militar: a constituição da sociedade civil no país e a construção da cidadania. Campinas: Unicamp, 2002. Dissertação (Mestrado) - Instituto de Filosofia e Ciências Humanas, Universidade de Campinas, 2002.

DIENSTMANN, G. Usos do passado e disputa pela memória no questionamento da lei de 1979 no Supremo Tribunal Federal. Porto Alegre: UFRGS 2010. Trabalho de Conclusão de Curso (História) - Instituto de Filosofia e Ciências Humanas, Universidade Federal do Rio Grande do Sul, 2010.

ELSTER, J. Rendicion de cuentas. La justicia transicional em perspectiva histórica. Buenos Aires: Katz, 2006.

GRECO, H. A. Anista anmnese vs. Anistia amnésia: a dimensão trágica da luta pela anistia. In. SANTOS, C. M.; TELES, É.; TELES, J. A. (Orgs.), Desarquivando a ditadura: memória e justiça no Brasil. São Paulo: Hucitec, 2009, pp. 524-540.

HALBWACHS, M. [1994]. Los marcos sociales de la memoria. Barcelona: Antthropos Editorial; Cencepción: Universidad de la Concepción; Caracas: Universidade Central de Venezuela, 2004.

HEYMANN, L. Q. O devoir de mémoire na França contemporânea: entre memória, história, legislação e direitos. In. GOMES, A. C. (Coord.). Direitos e cidadania: memória, políticae cultura. Rio de Janeiro: FGV, 2007, pp. 15-43. 
JELIN, E. Los trabajos de la memoria. Madrid: Siglo XXI, 2002.

MEZAROBBA, G. Entre Reparações, meias verdades e impunidades. O difícil rompimento com o legado da Ditadura no Brasil. SUR Revista Internacional de Direito Humanos, v. 7, n. 13, 2010, pp. 7-24.

MEZAROBBA, G. O Preço do esquecimento: as reparações pagas às vitimas do regime militar (uma comparação entre Brasil, Argentina $e$ Chile). São Paulo: USP, 2007. Tese (Doutorado) - Faculdade de Filosofia, Letras e Ciências Humanas, Universidade de São Paulo, 2007.

MEZAROBBA, G. O que é Justiça de transição? Uma análise do conceito a partir do caso brasileiro. In. SOARES, I. V. P.; KISHI, S. A. S. (Coord.). Memória e verdade: A justiça de transição no Estado Democrático brasileiro. Belo Horizonte: Fórum, 2009. pp. 37-53

MEZAROBBA, G. Um acerto de contas com o futuro: a anistia e suas consequências - um estudo do caso brasileiro. São Paulo: USP, 2003. Dissertação (Mestrado) - Faculdade de Filosofia, Letras e Ciências Humanas, Universidade de São Paulo, 2003.

O'DONNELL, G.; SCHIMITTER, P. Transições do regime autoritário. Primeiras conclusões. SP, Ed. Revista dos Tribunais, 1988.

POLLAK, M. Memória, esquecimento, silêncio. Estudos Históricos, v.2, n.3, 1989, pp. 3-15.

QUARTIM, M. L. O que é possível lembrar? Campinas: Cadernos Pagu, n. 40, janeiro-junho, 2013, pp.141-167.

QUINALHA, R. H. Justiça de Transição: contornos do conceito. São Paulo: Ed. Outras Expressões; Ed. Dobra Editorial, 2013.

RICOEUR, P. Memory, history, oblivion. Palestra proferida na Conferência Internacional <Haunting Memories? History in Europe after Authoritarianism>. Budapeste, 2003. Texto traduzido para português disponível no site da Universidade 
de Coimbra. Disponível em: <http://goo.gl/o2wHR9>. Acesso em 05 fev. 2015.

ROLEMBERG, D. Esquecimento das Memórias. In. MARTINS FILHO, J. R. (Org.). O Golpe de 1964 e o regime militar. São Carlos: Ed. UFSCar, 2006. pp. 81-91.

ROSITO, J. B. A. Anistia política, reparação econômica e justiça de transição: um estudo etnográfico das medidas brasileiras compensatórias por violações de direitos humano à época da ditadura militar. Painel apresentado durante II Reunião do Grupo de Estudos sobre Internacionalização do Direito e Justiça de Transição (IDEJUST), São Paulo, Cidade Universitária da USP, 2010. Disponível em <http://goo.gl/ zg6QoH>. Acesso em 25 jun. 2014.

ROTH-ARRIAZA, N. O papel dos actores internacionais nos processos nacionais de responsabilização. In. BRITO, A. B.; GONZÁLEZ, C.; FERNÁNDEZ, P. A. (Orgs.) A política de memória: verdade e justiça na transição para a democracia. Lisboa: Instituto de Ciências Sociais, 2004, pp. 63-86.

SANTOS, C. M. A justiça ao serviço da memória: mobilização jurídica transnacional,direitos humanos e memória da ditadura. In. SANTOS, C. M.; TELES, É.; TELES, J. A. (Orgs.). Desarquivando a ditadura: memória e justiça no Brasil, 2. São Paulo: Hucitec, 2009, pp. 472-493.

SELIGMANN-SILVA, M. Anistia e (in)justiça no Brasil: o dever de justiça e a impunidade. In. SANTOS, C. M.; TELES, É.; TELES, J. A. (Orgs.), Desarquivando a ditadura: memória e justiça no Brasil, 2. São Paulo: Hucitec, 2009, pp. 541-556.

TATAGIBA, L.; ABERS, R.; SERAFIM, L. Repertórios de atuação Estado-Sociedade em um Estado heterogêneo: A experiência na Era Lula. In: Revista DADOS - Revista de Ciências Sociais, v. 57, n. 2, 2014, pp. 325-357. 
TEITEL, R. How are the New Democracies of the Southern Cone Dealing with the Legacy of Past Human Rights Abuses? In. KRITZ, N. (Ed.). Transitional Justice: How Emerging Democracies Reckon with Former Regimes. Washington, DC: United States Institute of Peace Press, 1996, pp.146-153.

TELES, E. Políticas de silêncio e interditos da memória na transição do consenso. In. SANTOS, C. M.; TELES, É.; TELES, J. A. (Orgs.). Desarquivando a ditadura: memória e justiça no Brasil, 2. São Paulo: Hucitec, 2009, pp. 578-591.

TODOROV, T. [1995]. Los abusos de la Memoria. Barcelona: Ed. Paidós Ibérica, 2000.

TORELY, M. Memória, Verdade e Senso Comum Democrático: Distinções e aportes do "direito à memória e à verdade" para a substancialização democrática. REID - Revista Eletrônica de Direito e Cidadania, 2010. Disponível em <http://goo.gl/ cvVwC8>. Acesso em 27-05-2014.

VASCONCELOS, D. M. Memória Política, democracia, e accontability: algumas reflexões teóricas. Oficina do CES, n. 30, out. 2009. Centro de Estudos Sociais de Coimbra, Portugal, 2009. 